\title{
El tratamiento nominal camarada en la diacronía del español (sS. XVI-XX): un ejemplo de deixis social igualitaria*
}

The comrade Nominal Address Terms in the Diachrony of the Spanish Language (16th-20th Centuries): An Example of Social Egalitarian Deixis

Francisca MEdina Morales

Departamento de Lengua Española

Facultad de Filosofía y Letras, Universidad de Granada

Campus de Cartuja

Profesor Clavera, s/n. Granada, 18011

fmedina@ugr.es

Orcid ID 0000-0001-7737-1174
RECIBIDO: 20 DE MARZO DE 2020 ACEPTADO: 19 DE JUNIO DE 2020

\footnotetext{
María Á. LóPEZ-VALLEJO

Departamento de Didáctica de la lengua y la literatura

Facultad de Ciencias de la Educación y del Deporte, Universidad de Granada

Campus de Melilla

Santander, 1. Melilla, 52071

yerma111@ugr.es

Orcid ID 0000-0003-0965-2657
}

Resumen: Se lleva a cabo el análisis semánticodiacrónico del término camarada, desde su aparición en el xvi en contextos militares con el significado de 'soldado', hasta su uso actual como título de tratamiento ligado al partido comunista. Dicha forma áurea fue exportada en sus varias acepciones como préstamo a Europa con el imperio de Carlos I y, tras un proceso de variación estable en nuestra lengua, retornó al español como préstamo semántico con distintos significados: como 'obrero' (finales del XIX) y como 'correligionario' (primer tercio del xx). Postulamos así que camarada tuvo dos nacimientos en la historia del español, por lo cual entraría a formar parte del repertorio de resurrecciones léxicas que se registran en nuestra lengua. Tal fenómeno ha sido categorizado en la teoría del cambio léxico como poligénesis temporal. Asimismo, se analiza la variación de camarada como forma de tratamiento nominal ligada a un esquema de deixis social igualitaria, esto es, a un uso simétrico y recíproco de la pauta pronominal inserta dentro de la dimensión de solidaridad.

Palabras clave: Cambio semántico. Tratamientos nominales. Deixis igualitaria. Diacronía del español. * Este trabajo se inscribe en el proyecto I+D HISPATEST, de referencia FFI2017-83400-P (MINECO/
AEI/FEDER/UE). 
Abstract: In the present work a semantic and diachronic analysis of the term camarada ('comrade') is carried out, from its origin in the sixteenth century in military contexts with the meaning of 'soldier', to its current use as a title of treatment linked to the communist party. This form was exported through its various meanings as a loan to Europe with the empire of Charles I and, after a process of stable variation in our language, it returned to Spanish as a semantic loan with different meanings: as 'labourer' (end of the 19th Century) and as 'coreligionist' (at the beginnings of the 2oth Century). We claim that camarada had two births in the his- tory of the Spanish language, and, therefore, it would become part of the repertoire of lexical resurrections recorded in our language. This phenomenon has been categorized in the theory of lexical change as temporal polygenesis. Likewise, the variation of camarada is analysed as a form of nominal treatment linked to an egalitarian social deixis frame, that is, to a symmetrical and reciprocal use of the pronominal pattern within the solidarity dimension.

Keywords: Semantic Change. Nominal Treatments. Egalitarian Deixis. Spanish Diachrony.

\section{CAMARADA EN EL CONTEXTO HISTÓRICO-SOCIAL}

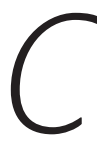

amarada, en su origen 'soldado, compañero de cámara', se expandió por toda Europa en el XVI gracias a la labor de los tercios, el primer ejército moderno europeo, fundado por el emperador Carlos I. Los soldados de los tercios eran hombres de honor, disciplinados y unidos por lazos semejantes a los de la sangre; entre ellos se llamaban camaradas y, aunque había diferencias en el campo de batalla, todos eran iguales en el trato personal (ver Parker). Así, camarada se convirtió en una palabra internacional y fue incorporada como préstamo a todas las lenguas europeas: comrade (ing.), Kamerad (al.); camarata (ital.), camarada (port.), camarad (rum.), kamerat (nor.), kammerat (danés); kamrat (sueco).

Hacia la segunda mitad del XVIII, la Revolución industrial en Inglaterra (1760) y la Revolución francesa (1789) actuaron como catalizador en Europa de una nueva sensibilidad en el tratamiento. En la Revolución industrial, las primeras asociaciones de obreros eliminaron las diferencias en el tratamiento a partir de las convicciones económicas, $\mathrm{y}$, entre los títulos, usaron comrade como trato igualitario entre ellos; también el Socialismo, nacido en Alemania, adoptó kamrade, trato afectuoso entre quienes compartían las ideas socialistas (ver Rudé). De la Revolución burguesa de 1789, también resultó una nueva forma de tratamiento en igualdad para la mayoría social: citoyen 'ciudadano', que suprimía los títulos del Antiguo Régimen (ver McPhee). Casi un siglo después, la Revolución rusa de 1917 se hace eco de la nueva sensibilidad europea en el tratamiento igualitario. Si bien en Rusia nunca se consideró el trato de ciudadano, ya que implicaba derechos y libertades democráticas, se asumió la igualdad imperante con tovarisch, tratamiento que eliminaba la asimetría a par- 
tir de las convicciones ideológicas comunistas (ver Olliver). En el primer tercio del Xx, camarata se usó en Italia como tratamiento igualitario entre los fascistas de Mussolini, y Kamerad, en la Alemania nazi, entre los miembros del partido (ver Tortella).

El marco histórico descrito vendría a corroborar la tendencia general de las lenguas occidentales a la dimensión de solidaridad y al predominio de las relaciones simétricas con el aumento del tuteo recíproco igualitario, esto es, la tendencia al tratamiento único (Brown/Gilman).

\section{HIPÓTESIS}

Partimos de que camarada es un tratamiento nominal con doble nacimiento en la historia del español. Apareció como neologismo y título nominal en el español del XVI, época en la que se incorporó al esquema de trato solidario, reflejando distintos vínculos y adaptándose a contextos diversos. Se conservó en el discurso de las centurias posteriores en alternancia con otros títulos más generales como amigo o compañero, o títulos de parentesco como bermano, los cuales casi llegaron a eclipsarlo, hasta que camarada resurge y gana vitalidad como préstamo semántico llegado de Europa: a finales del XIX, a través de los movimientos obreros de la Revolución industrial y, a comienzos del xx, en un segundo reemplazo, a través de Fascismo italiano.

\section{OBjetivos}

El objetivo general es trazar, de un lado, la primera biografía del título nominal de tratamiento camarada, que se ha revelado como uno de los préstamos de nuestra lengua con mayor proyección internacional desde el XVI hasta hoy. De otro lado, se trata de mostrar la enorme importancia que ha tenido en su conservación una variable no estrictamente social, como es el cambio semántico.

Los objetivos específicos son:

a) Analizar en profundidad el cambio semántico del término camarada en la diacronía del español, haciendo para ello tres cortes que coinciden con etapas singulares de la historia de nuestra lengua.

b) Estudiar los patrones de variación del tratamiento nominal camarada y su conservación en la deixis social igualitaria. Enmarcamos dicha forma y su esquema de trato dentro de la tendencia descrita de las lenguas occidentales hacia el eje de la solidaridad. 


\section{CORPuS}

El corpus base se compone de una selección de 430 documentos, que arrojan un total de 879 ocurrencias. Dichos documentos abarcan un amplio periodo comprendido entre el XVI y último tercio del XX y se distribuyen en tres cortes en diacronía: XVI y XVII (1552-1699), XVIII y XIX (1703-1897) y XX (1905-2002).

Para cada centuria, se ha seleccionado un promedio de cien documentos, repartidos entre tipos textuales diferentes de una forma lo más equitativa posible, si bien, en algunos casos, ha prevalecido el interés del texto y su aportación al fenómeno analizado.

\begin{tabular}{c|cc}
\hline$X V I$ & $15.10 \%$ & $(131 / 879)$ \\
\hline$X V I I$ & $27.90 \%$ & $(246 / 879)$ \\
\hline$X V I I I$ & $10.01 \%$ & $(88 / 879)$ \\
\hline$X I X$ & $23.09 \%$ & $(203 / 879)$ \\
\hline$X X$ & $23.89 \%$ & $(210 / 879)$ \\
\hline
\end{tabular}

Tabla 1. Frecuencia de las ocurrencias en el corpus.

El corpus de control se ha configurado teniendo en cuenta como fuentes primarias diccionarios, gramáticas y obras lingüísticas, que proporcionan información para reconstruir las distintas etapas del cambio, tanto en el plano del significado, como en lo referente a la pauta del tratamiento. Como fuentes secundarias, manejamos el CNDH, a partir del cual disponemos de un gran banco de datos de tipo documental.

\subsection{Tipología textual}

El corpus base está integrado por textos literarios y no literarios, en una proporción aproximada del cincuenta por ciento de media. Así, se ha intentado superar las limitaciones de los corpus diseñados con un patrón estrictamente literario y, en consecuencia, que las conclusiones se extiendan con mayor amplitud a otras manifestaciones textuales.

a) Textos literarios: novelas y piezas teatrales, seleccionadas por su interés sociolingüístico y pragmático. Se plantea, ante todo, la verosimili- 
tud de la lengua reproducida y, por ello, se ha cuidado que las obras tengan rasgos de inmediatez y espontaneidad comunicativas Dichos textos, además de permitirnos determinar la variación semántica, proporcionan el patrón de variación como tratamiento nominal.

b) Textos no literarios: tratados militares, crónicas, obras de costumbres, documentos de la administración pública y eclesiásticos, bandos políticos, discursos, ensayos filosóficos, memorias, cartas oficiales y, minoritariamente, periódicos (solo para la segunda mitad del xx). Como rasgos textuales, destaca en algunos de ellos un tipo de discurso muy codificado, con rigidez en las estructuras y, a veces, una retórica y estilo solemne, que sirve de contrapunto a la cercanía de la variedad literaria.

\section{Metodología}

Las bases metodológicas sobre las que se sustenta este análisis son:

a) Para estudiar el cambio semántico, se ha considerado la perspectiva teórica clásica que vincula el cambio semántico y el cambio histórico -Álvarez de Miranda (1992); García-Godoy (1999)-. Partimos de que los factores extralingüísticos (innovaciones políticas, sociales, económicas) repercuten en la lengua como impulsores del cambio.

b) A la hora de examinar los patrones de variación del tratamiento nominal, partimos del enfoque sociolingüístico (Brown/Gilman), es decir, se analizan los factores sociales que pautan los tratamientos de solidaridad, el sistema de deixis social codificado junto con las estrategias de cortesía que manipulan dicho sistema, condicionando la elección del tratamiento; adoptamos, asimismo, una perspectiva pragmática (Brown/Levinson).

\section{Camarada En el Siglo de Oro}

\subsection{Surgimiento y consolidación}

En los siglos XVI y XVII, camarada surge en el estándar y se comienza a emplear con varias acepciones, entre ellas: "El compañero de cámara, que come y duerme en una mesma posada. Este término se usa entre soldados, y vale compañero y amigo familiar, que está en la mesma compañía" (Covarrubias, s.v. Ver también 
Oudin, DAut). ${ }^{1}$ Camarada saltó del ámbito militar y se popularizó entre la sociedad, ganando acepciones en una polisemia torrencial no sistematizable en etapas. ${ }^{2}$

\begin{tabular}{l|c}
\hline 'amigo' & $53.84 \%(203 / 377)$ \\
\hline 'soldado' & $18.03 \%(68 / 377)$ \\
\hline 'colectivo de amigos' & $14.00 \%(53 / 377)$ \\
\hline 'colectivo de soldados' & $8.20 \%(31 / 377)$ \\
\hline 'colectivo de la germanía' & $1.80 \%(7 / 377)$ \\
\hline 'pícaro' & $3.90 \%(15 / 377)$ \\
\hline
\end{tabular}

Tabla 2. Acepciones y frecuencia en el XVI y XVII.

De entre estas acepciones, la de mayor rentabilidad es 'amigo' y la de menor rendimiento, 'pícaro'. Esta última se incorporó tardíamente a la germanía en la segunda mitad del XVII -no la registra Hidalgo- y es un ejemplo del descenso sociolingüístico del término al marginalismo; por otra parte, nunca llegó a difundirse en el estándar y queda atestiguado exclusivamente en textos literarios picarescos (Medina Morales 2005b).

El uso de camarada como 'colectivo' tuvo importancia como variable en coocurrencia con otra acepción: 'junta de amigos', según registran los principales diccionarios de los siglos XVII y XVIII (DAut, s.v. Ver también Covarrubias; Oudin). A este respecto, nuestro corpus base arroja los primeros testimonios de camarada con el valor de 'junta de soldados' -en un contexto militar- y 'junta de pícaros', acepciones que obvian los diccionaristas de la época y los estudiosos del léxico histórico de germanía (Chamorro; Alonso Hernández).

Primera documentación de camarada, en un texto militar: 'soldado'

(1) Porque cada ruin, con el fauor de otros tales de sus camaradas se le yria. (1552 Núñez Alba)

1. En cuanto a los diccionarios, citamos de forma individual solo los no incluidos en el NTLLE.

2. La vitalidad y rápida extensión del término se ampara en el hecho de que este fue un periodo de incontables campañas militares, en las que intervenía, junto al ejército profesional, la mayoría social (ver Parker). 
'junta de soldados'

(2) Otrosí, porque gran parte de la soldadesca buena consiste en que los soldados tengan camaradas de las cuales procede poderse sustentar con el sueldo mejor. (1568 Londoño)

'amigo'

(3)

a. Todos los soldados de la compañía han de entender y tener al capitán por padre [...], no se ha de arrimar hacer más por $c a$ maradas o por amigos. (1593 Isaba)

b. El primero que se topa cerca de donde se da una música les embiste con sus amigos y camaradas. (1602 Luján)

'junta de amigos'

(4) Y procuré d'estar con la camarada de los caballeros que eran entre comendadores. (1558 Anónimo)

'pícaro'

(5) Es gente movible [...] dicen voacé, so compadre, so camarada, y llaman media janega a la media azumbre. (1611 Quevedo)

'junta de pícaros'

(6) Éramos ocho de camarada, sin otras tantas amigas que llevábamos: uno se fingía mudo. (1602 Luján)

\begin{tabular}{l|c|c} 
& Textos literarios & Textos no literarios \\
\hline 'amigo' & $62 \%(125 / 203)$ & $38 \%(78 / 203)$ \\
\hline 'soldado' & $29 \%(19 / 68)$ & $71 \%(49 / 68)$ \\
\hline 'colectivo de soldados' & $17 \%(9 / 53)$ & $83 \%(44 / 53)$ \\
\hline 'colectivo de amigos' & $67 \%(20 / 31)$ & $33 \%(11 / 31)$ \\
\hline 'colectivo de pícaros' & $100 \%(7 / 7)$ & \\
\hline 'pícaro' & $100 \%(15 / 15)$ & \\
\hline
\end{tabular}

Tabla 3. Acepciones y distribución en los tipos textuales.

Al correlacionar la variable semántica con la tipología textual, queda reflejado el grado de dependencia de determinadas acepciones respecto del tipo de do- 
cumento. La acepción más libre es 'amigo', en tanto que 'soldado' se muestra muy dependiente del tipo discursivo, pues el corpus registra el mayor número de ocurrencias en tratados militares y crónicas. El uso como 'colectivo' en coocurrencia con 'amigo' y 'soldado' tuvo una frecuencia muy parecida a la de estas acepciones consideradas individualmente en ambos tipos textuales; los significados derivados de la germanía tienen absoluta dependencia de los textos literarios. Finalmente, los textos literarios se presentan como los más rentables para el análisis de la variación semántica, ya que en ellos se despliegan todas las acepciones.

\subsection{Camarada en estructuras sintagmáticas con valor semántico-pragmático}

Para la etapa áurea, destaca la presencia de camarada en determinadas estructuras sintagmáticas de elevada fijación y escasas variaciones estilísticas, de cierta complejidad, dada la acumulación de títulos, y con un uso muy generalizado determinado por su valor semántico-pragmático.

\begin{tabular}{|c|c|}
\hline Posesivo + camarada & $36.60 \%(67 / 183)$ \\
\hline Camarada + amigo, compañero & $21.31 \%(39 / 183)$ \\
\hline Camarada + hermano & $12.02 \%(22 / 183)$ \\
\hline Camarada + título del ejército & $10.38 \%(19 / 183)$ \\
\hline Adjetivo + camarada & $8.70 \%(16 / 183)$ \\
\hline Camarada (vocativo) & $6.55 \% \quad(12 / 183)$ \\
\hline Camarada + otro título & $4.37 \%(8 / 183)$ \\
\hline
\end{tabular}

Tabla 4. Rentabilidad de las estructuras sintagmáticas. ${ }^{3}$

En cuanto a la actualización de camarada, el posesivo en primera persona (mi camarada) constituye el procedimiento más habitual y, de forma muy aislada, encontramos otros actualizadores. Es la estructura de mayor fijación con una elevada frecuencia y se percibe como un marcador pragmático del máximo

3. De las 377 ocurrencias para el XVI y XVII, 183 se presentan insertas en tipo de patrones sintácticos. 
grado de cercanía; el de menor rendimiento corresponde a camarada + otros títulos (caballero, señor), que denotan un trato distante, inapropiado del título solidario camarada. ${ }^{4}$

Los adjetivos usados constituyen un repertorio poco amplio y tienen significados afectuosos (bueno, valiente) y de ponderación del vínculo (querido, antiguo).

(7)

a. Antes de tomar posada, le pregunté a mi camarada qué pensaba hacer. (1605 López Úbeda)

b. Se despidió mi buen camarada, y el villano quedó contando con los dedos. (1619 García)

El conglomerado camarada + otros títulos como amigo, hermano, que refuerzan la solidaridad, tiene una elevada rentabilidad (amigo: $21.31 \%$; hermano: $12.02 \%$ ) y aparece asociado a las posiciones sociales menos altas: soldados, germanía.

(8) Camarada hermano, no es honra nuestra / que nos quedemos acá. (1580 Ávila/Arguijo)

En los tratados militares, tradición discursiva muy fructífera en la España áurea por la belicosidad del momento histórico, manifiesta una alta frecuencia camarada + grado militar (camarada capitán, camarada sargento). Son causas contextuales las que explican este refuerzo aposicional: camarada implicaba un trato igualitario fuera del campo de batalla, donde desaparecen las jerarquías, pero no en otras circunstancias. Por tanto, dicha combinación sintagmática tenía un gran peso semántico-pragmático y, en estos tratados, alcanzaron un elevado grado de habitualización.

(9)

a. En la catana, fue el capitán camarada del Adelantado en aquel pasaje de tres días. (1612 Castro)

b. Lisardo se llama y es un soldado camarada. (1629 Calderón)

Si correlacionamos las estructuras sintagmáticas en que se inserta camarada con los tipos de textos, obtenemos el grado de flexibilidad textual respecto de dichos patrones sintácticos:

4. Para usos referenciales de mi camarada don + nombre de pila en las Novelas ejemplares de Cervantes, ver Iglesias Recuero (apartado 3) en este mismo volumen. 


\begin{tabular}{l|c|c} 
& TeXtos LITERARIOS & TEXTOS no LITERARIOS \\
\hline Posesivo + camarada & $55.20 \%(37 / 67)$ & $44.77 \%(30 / 67)$ \\
\hline Camarada + amigo & $56.41 \%(22 / 39)$ & $43.58 \%(17 / 39)$ \\
\hline Camarada + hermano & $81.81 \%(18 / 22)$ & $18.18 \%(4 / 22)$ \\
\hline Camarada + título del ejército & $21.05 \%(4 / 19)$ & $78.94 \%(15 / 19)$ \\
\hline Adjetivo + camarada & $75.00 \%(12 / 16)$ & $25.00 \%(4 / 16)$ \\
\hline Camarada (vocativo) & $58.33 \%(7 / 12)$ & $41.66 \%(5 / 12)$ \\
\hline Camarada + otro título & $25.00 \%(2 / 8)$ & $75.00 \%(6 / 8)$ \\
\hline
\end{tabular}

Tabla 5. Estructuras y flexibilidad textual.

El grado de cercanía del texto es directamente proporcional a la frecuencia de las estructuras proclives al trato solidario; en este sentido, destacan los textos literarios como los que registran el mayor número de esquemas sintácticos de este tipo (posesivo + camarada camarada amigo; camarada + bermano) y, por tanto, se presentan como los más rentables para el análisis de camarada como título igualitario, frente a los documentos que limitan las combinaciones, muchos de ellos anclados en los cánones propios de sus tradiciones discursivas.

\subsection{Camarada como marcador de la simetría}

Camarada se configura como tratamiento nominal en las relaciones simétricas, tanto en las que predomina la familiaridad como en las que lo hace la formalidad. La rápida popularización del término, desde contextos militares hasta el estándar cotidiano, la codificó en la deixis social como un título de trato solidario integrador, que no venía determinado por el estatus: se situó en un terreno conciliador en la interacción lingüística y nunca estuvo marcado por actitudes negativas de las distintas clases sociales. Este prestigio es muy relevante en un periodo en el que destaca la postura cautelosa y desconfiada de la sociedad respecto de los tratamientos, pues la movilidad social y la pérdida de valores tradicionales heredados generaba importantes roces asociados al paradigma de la cortesía (Medina Morales 2005a). 
6.3.1 Relaciones simétricas en las que predomina la familiaridad ${ }^{5}$

\begin{tabular}{l|ll}
\hline Contexto tuteante & $24.70 \%$ & $(22 / 89)$ \\
\hline Contexto voseante & $75.20 \%$ & $(67 / 89)$ \\
\hline
\end{tabular}

Tabla 6. Paradigma de la 2. ${ }^{a}$ persona. ${ }^{6}$

\section{a) Contextos tuteantes}

El paradigma camarada + tú fue menos frecuente que el voseante. En el XVI y XVII, el tuteo recíproco constituía un marcador lingüístico del más alto grado de solidaridad entre los hablantes y únicamente se empleó cuando existía una estrecha relación de afectividad. Este tú no fue descrito en las gramáticas áureas, a excepción de Correas: "De tú se trata a los muchachos i menores de la familia, i a los que se quisieren bien" (368).

(10) Soltáronsete -dijo don Cleofás- los consonantes, camarada. (1641 Vélez)

Camarada + título de parentesco + tú, cuando no había un vínculo familiar real, identifica al estatus más bajo en el trato entre amigos o conocidos. De esta forma, se veía reforzada la intimidad y se expresaba una gran solidaridad de clase.

(11) Hola, hermano Jacobo, hágote saber que tengo en el asador un muy gentil torrezno. Pan hay: si tienes vino, serás mi compañero; y si no, perdona, que quiero buscar camarada. (1599 Alemán)

\section{b) Contextos voseantes}

Camarada + vos en simetría retrataba un vínculo de amistad, al tiempo que podía corresponder a otro más superficial entre conocidos. Al cubrir un dilatado continuum de relaciones, fue la pauta más rentable para la familiaridad en el XVI y XVII.

5. La simetría en las relaciones se manifiesta a través de la reciprocidad en los tratamientos (Brown/Gilman).

6. El corpus arroja 377 ocurrencias para el XVI y XVII, de las cuales 132 reflejan la interacción lingüística que permite analizar la pauta de trato ( 89 para la 2. ${ }^{a}$ persona y 43 para la $3 .^{a}$ persona). No se ha mostrado relevante la correlación entre la variable semántica y la variación en el tratamiento; asimismo, esta es independiente del tipo textual. 
De vos tratamos a los criados i mozos grandes, i a los labradores i a personas semexantes; i entre amigos adonde no ai gravedad ni cumplimiento se tratan de vos (Correas 368).

En este sentido, es notable la presencia del título nominal camarada a la hora de asegurar la cercanía, junto a un pronombre vos multifuncional y desgastado.

(12) Vos seréis mi camarada. (1606 Lope Vega)

Se documentan algunos casos hibridos de trato simétrico familiar, en los que el interlocutor alterna vos/tú para el mismo vínculo y en idéntica situación, que vendrían a constatar que ambos pronombres tuvieron en determinados contextos un valor afectivo idéntico.

(13) No entendí, camarada, que me habías conocido. ¿Cómo os va, amigo? (1611 Quevedo)

6.3.2 Relaciones simétricas en las que predomina la formalidad

\begin{tabular}{l|ll}
\hline Túlvos & $67.42 \%$ & $(89 / 132)$ \\
\hline V.m. & $32.57 \%(43 / 132)$ \\
\hline
\end{tabular}

Tabla 7. Paradigma de $2 .^{a}$ y $3 .^{a}$ persona.

Camarada $+v \cdot m$. como trato en simetría tuvo un menor rendimiento, frente al paradigma de 2. ${ }^{a}$ persona, a pesar de que la etapa áurea se caracterizó por el predominio de la formalidad, incluso en la dimensión de solidaridad. En este periodo, es relevante que v.m. recíproco tuviera, igual que vos, una elevada funcionalidad y marcara la pauta de las relaciones tanto entre amigos íntimos como entre conocidos. No obstante, camarada mostró preferentemente su tendencia a la díada de $2 .^{a}$ persona voseante, frente a la de $3 .^{a}$ persona, pauta en la que el título se erige en marcador pragmático que asegura una cortesía más cercana y afectuosa.

(14) ¿Quiere jugar, camarada? (1613 Vélez) 
Se registran ejemplos aislados de camarada + señor $+v . m$., usos muy formales poco apropiados para un título solidario como camarada. Son razones pragmáticas determinadas por la tradición discursiva las que explican este empleo, documentos solemnes con un valor enfático.

(15) El general, sonriendo, me dijo: "Señor camarada, no se enoje vuestra merced". (1607-1645 Estrada)

\section{CAMARADA EN EL XVIII Y XIX}

\subsection{Hacia la resurrección léxica}

Camarada se registra en todas las obras lexicográficas publicadas en estos dos siglos (Sobrino; Steven; Bluteau). En el DAut, aparece con el significado de 'amigo', y también como colectivo: "los que andan en quadrilla juntos" (s.v.), pero no hay alusión al significado militar de 'soldado'. En el último tercio del XIX, Terreros y Pando definió camarada: "Compañero, asociado, amigo. En la milicia usan mucho de la voz camarada aun los mismos oficiales respecto de los soldados" (s.v.).

\begin{tabular}{l|c|c} 
& SicloxVIII & SictoxIX \\
\hline 'amigo' & $39.77 \%(35 / 88)$ & $45.32 \%(92 / 203)$ \\
\hline 'soldado' & $53.40 \%(47 / 88)$ & $34.97 \%(71 / 203)$ \\
\hline 'colectivo de soldados' & $4.54 \%(4 / 88)$ & $6.40 \%(13 / 203)$ \\
\hline 'colectivo de amigos' & $2.27 \%(2 / 88)$ & $8.37 \%(17 / 203)$ \\
\hline 'compatriota' & & $2.90 \%(6 / 203)$ \\
\hline 'proletario' & & $1.97 \%(4 / 203)$ \\
\hline
\end{tabular}

Tabla 8. Acepciones en el XVIII y XIX.

El corpus evidencia un proceso gradual de debilitamiento de camarada a lo largo del XVIII, centuria en que se localizan pocas ocurrencias en comparación con los siglos precedentes; asimismo, un elevado porcentaje de estas conserva el originario significado militar del 'soldado', en detrimento del más general de 'amigo'. 
El proceso de variación léxica más interesante se produce en el XIX. $\mathrm{Ca}$ marada se reactiva en el uso y se presenta como una variable con alto grado de rentabilidad, presente en contextos muy variados donde despliega numerosas acepciones. Se conservan las antiguas de la milicia ('soldado'/'junta de soldados'), en alternancia con 'amigo', que gana fuerza independientemente del tipo discursivo. La neología semántica se inicia en la segunda mitad del XIX, etapa en la que se produce la resemantización del término: surge una nueva acepción, 'compatriota' (1868) y, de otra parte, en 1886, se localiza camarada, por vez primera, en un ensayo filosófico, como 'obrero'. Subrayamos la gran importancia de este hallazgo, que refleja el préstamo semántico importado de Europa y proveniente de forma simultánea del inglés comrade, del alemán $\mathrm{Ka}$ merad y del francés camarade, vocablos usados a lo largo del XIX, en sus respectivos países, para designar a los miembros de las asociaciones obreras, surgidas en la Revolución industrial. ${ }^{7}$ Las siguientes palabras del Manifiesto comunista (1848) vienen a esclarecer cómo se produjo en Europa la resemantización de camarada 'soldado', que ganó la acepción de 'obrero':

Masas de obreros, hacinados en la fábrica, están organizados en forma militar. Como soldados rasos de la industria, están colocados bajo la vigilancia de una jerarquía completa de oficiales y suboficiales. (Marx/Engels 28-29)

Dicho préstamo coincide con el periodo en el que, en España, hay un predominio de las acepciones 'amigo' y 'soldado'.

a) 'amigo'

(16) ¿Sabes que advierto que esta tu gente y camaradas, si son valerosos en el pelear, no son muy escrupulosos en la fe? (1852 Cánovas)

b) 'soldado'

(17) Entre estos soldados menudos los hay de todas las clases sociales [...]. Todos iguales ante sus jefes se han convertido en camaradas. (1885 Blasco)

7. La Revolución industrial, iniciada en Gran Bretaña y extendida por toda Europa, trajo consigo la aparición de una nueva clase trabajadora, que vivía en unas condiciones pésimas. Dicha clase se organizó para la defensa de sus intereses en movimientos obreros, auspiciados por las ideas socialistas y anarquistas. Desde el principio, fue concebido como un movimiento internacional (ver Martínez de Velasco; Rudé). 
c) 'compatriota'

(18) A sus compatriotas y camaradas se dirigía en una corta proclama. (1868 Pirala)

d) 'obrero'

(19) En Glasgow se cegaba con ácido sulfúrico a dos obreros que no habían querido hacer causa común con sus camaradas; con posterioridad, en Sheffield se volaba la casa del obrero. (1886 Aller)

A continuación, se correlaciona la frecuencia de las acepciones con la tipología textual:

\begin{tabular}{l|c|c} 
& Textos literarios & Textos no literarios \\
\hline 'amigo' & $54.28 \%(19 / 35)$ & $45.71 \%(16 / 35)$ \\
\hline 'soldado' & $46.80 \%(22 / 47)$ & $53.19 \%(25 / 47)$ \\
\hline 'colectivo de soldados' & $25.00 \%(1 / 4)$ & $75.00 \%(3 / 4)$ \\
\hline 'colectivo de amigos' & $100.00 \%(2 / 2)$ & \\
\hline
\end{tabular}

Tabla 9. Significado dieciochesco y tipología textual.

\begin{tabular}{l|c|c} 
& Textos literarios & Textos no ltterarios \\
\hline 'amigo' & $63.04 \%(58 / 92)$ & $36.95 \%(34 / 92)$ \\
\hline 'soldado' & $42.25 \%(30 / 71)$ & $57.74 \%(41 / 71)$ \\
\hline 'colectivo de soldados' & $30.76 \%(4 / 13)$ & $69.23 \%(9 / 13)$ \\
\hline 'colectivo de amigos' & $64.70 \%(11 / 17)$ & $35.29 \%(6 / 17)$ \\
\hline 'compatriota' & & $100.00 \%(6 / 6)$ \\
\hline 'obrero' & & $100.00 \%(4 / 4)$ \\
\hline
\end{tabular}

Tabla 10. Significado decimonónico y tipología textual.

Los documentos literarios se muestran como los de mayor flexibilidad para el despliegue de la polisemia en el XVIII, en tanto que, en el XIX, revelan un mayor interés los no literarios, que vienen a documentar las resemantizaciones. 
En el cuadro siguiente, se segmenta el XIX en tres periodos y, para cada uno, se lleva a cabo la selección de 5 documentos no literarios, que son los que reflejan con mayor claridad las etapas del cambio. Se constata la frecuencia absoluta de camarada en cada uno de ellos para mostrar la disminución de su empleo con el significado de 'soldado', y el avance de la acepción 'amigo' a lo largo de la centuria. Este uso privilegiado abona el terreno para que se abra paso la nueva acepción importada del extranjero: 'obrero'.

\begin{tabular}{l|c|c|c} 
& $1804-1837$ & $1840-1875$ & $1877-1886$ \\
\hline 'amigo' & $33.33 \%(4 / 12)$ & $58.33 \%(7 / 12)$ & $50.00 \%(9 / 18)$ \\
\hline 'soldado' & $66.66 \%(8 / 12)$ & $41.66 \%(5 / 12)$ & $27.77 \%(5 / 18)$ \\
\hline 'obrero' & & & $22.22 \%(4 / 18)$ \\
\hline
\end{tabular}

Tabla 11. Etapas del cambio.

No se puede concluir que camarada haya protagonizado en el XVIII un proceso de discontinuidad léxica, sensu stricto, con respecto a la etapa áurea, pues nunca llegó a extinguirse, aunque algunas acepciones desaparecieran y otras perdieran frecuencia. No obstante, es un hecho que camarada resurgió a finales del XIX como préstamo semántico y esta resurrección léxica ${ }^{8}$ debe explicarse aludiendo al concepto de poligénesis temporal. ${ }^{9}$

\subsection{Variación sintagmática de un título con tradición}

En los siglos XVIII y XIX, se simplifica en gran medida la variación sintagmática en la que se integra el término camarada en comparación con la etapa precedente. Este hecho respondería a varias causas: de un lado, la nueva sensibilidad ilustrada y romántica, que relaja el gusto por los omnipresentes títulos sociales de la época áurea; de otro, la tradición y habitualización de camarada, título nominal con raíces y totalmente incorporado, tanto en la lengua cotidiana, como en los tipos discursivos con un gusto más ceremonial, como tra-

8. Aquí no sería muy exacto hablar de resurrección, ya que la voz nunca estuvo muerta en el momento en que tuvo lugar su reciclaje (Álvarez de Miranda 2008, 15); además, nada impidió que se siguiera usando con las antiguas acepciones, 'soldado' y 'amigo'.

9. La historia del tratamiento madama también revela un proceso de poligénesis temporal en la historia del español (ver García-Godoy, apartado 1, en este mismo volumen). 
tamiento simétrico en igualdad, independientemente del pronombre correferencial.

Es indicativo el avance de la composición en formulismos de tratamiento igualitario más cercano, que se adecúan fundamentalmente a la expresión del trato afectuoso entre los hablantes. Sobresale la actualización por medio de posesivos y la modificación por medio de adjetivos calificativos (valiente camarada), así como la sufijación con el diminutivo, usurpando el hueco a estructuras más complejas, formulismos áureos que integraban varios títulos ( $c a-$ marada + título del ejército; camarada + caballero, señor; camarada + títulos de parentesco). En consecuencia, todas las variantes tienen un elevado valor pragmático y reflejan la vitalidad de camarada, su arraigo, así como su flexibilidad y adaptación a una nueva sensibilidad en el tratamiento igualitario, donde, ante todo, se marca la cercanía y el afecto sin condicionamientos sociales y dependiente de preferencias estilísticas. En el siguiente cuadro se reflejan estas estructuras:

\begin{tabular}{l|c|c} 
& SIcLoxVIII & SIcLoxIX \\
\hline Posesivo + camarada & $11.19 \%(15 / 134)$ & $23.88 \%(32 / 134)$ \\
\hline Camarada + título del ejército & $20.14 \%(27 / 134)$ & $8.90 \%(12 / 134)$ \\
\hline Camarada + sufijo diminutivo & $2.90 \%(4 / 134)$ & $17.16 \%(23 / 134)$ \\
\hline Adjetivo + camarada & $6.70 \%(9 / 134)$ & $8.90 \%(12 / 134)$ \\
\hline
\end{tabular}

Tabla 12. Estructuras sintagmáticas en el XVIII y XIX..$^{10}$

La más frecuente es posesivo + camarada, con el que se expresa el máximo grado de cercanía y la menos rentable es camarada + título del ejército, pues se trata de una estructura muy dependiente de un tipo discursivo (obras militares, crónicas), más fértil en el XVIII que en el XIX, época en que cobraron mayor relevancia los acontecimientos sociopolíticos que los militares. ${ }^{11}$ En el XIX, camarada + título del ejército aparece en documentos ceremoniosos herederos de la etapa anterior, en los que el título militar se constituye en un marcador

10. De las 291 ocurrencias para estos siglos, 134 se presentan insertas en este tipo de patrones sintácticos.

11. España, en el XIX, se caracterizó por un antimilitarismo predominante, que, a finales de siglo, creció por influencia del movimiento obrero, que, en general, atacó al ejército (ver Comellas). 
solemne, pues una menor frecuencia de uso conlleva un mayor peso pragmático.

a. Camarada comandante: Si mi padre ha muerto, aún vivo yo, sobre esos perros, camaradas. (1871 Fernández)

b. Os lo promete vuestro General camarada, a quien, como siempre, veréis pelear como capitán y como soldado. (1863 Díaz)

En el cuadro siguiente, presentamos tres cortes diacrónicos en el XVIII y para cada uno se han seleccionado cinco obras. Se constata la frecuencia absoluta de apariciones de camarada en cada una de ellas para mostrar la disminución del empleo del título en estructuras complejas y el avance del posesivo y diminutivo a lo largo de la centuria.

\begin{tabular}{l|c|c|c} 
& $1706-1740$ & $1751-1778$ & $1778-1795$ \\
\hline Camarada + título del ejército & $83.33 \%(10 / 12)$ & $60.00 \%(9 / 15)$ & $50.00 \%(8 / 16)$ \\
\hline Posesivo + camarada & $16.66 \%(2 / 12)$ & $26.66 \%(4 / 15)$ & $37.50 \%(6 / 16)$ \\
\hline Camarada + sufijo diminutivo & & $13.33 \%(2 / 15)$ & $12.50 \%(2 / 16)$ \\
\hline
\end{tabular}

Tabla 13. Disminución del empleo en estructuras complejas.

En las construcciones posesivas, este determinante no es un simple presentador formulaico, sino un importante refuerzo del vínculo afectivo:

a. Mi camarada y mi pariente: igran mozo! (1767 De la Cruz)

b. [...] formando pareja con cierto inglés, mi camarada en la aventura. (1847 Estébanez)

En el XIX, hay un incremento muy importante en el empleo del diminutivo con una gran flexibilización, ya que está presente en estatus sociales muy diferentes y con un gran peso pragmático:

a. Es decir, yo sin la capa y mi camaradilla sin el cigarro. (1847 Estébanez)

b. En buen apuro me vi, camaraíta -dijo Villalonga. (1885-1887 Galdós) 


\subsection{Camarada como tratamiento amistoso y formal}

La formalidad presidió los tratamientos en el español del XVIII y XIX, y esto se manifestó incluso en un vínculo de confianza como es la amistad. En este marco de deferencia se inserta camarada, como tratamiento simétrico o igualitario cuyo correlato pronominal podía ser el tú o usted recíproco. Este último fue el de mayor rendimiento para del trato amistoso, tanto cercano como superficial. ${ }^{12}$

\begin{tabular}{|c|c|}
\hline Usted & $72.89 \%(78 / 107)$ \\
\hline Tú & $27.10 \%(29 / 107)$ \\
\hline
\end{tabular}

Tabla 14. Camarada en paradigmas de $2 .^{\mathrm{a}}$ y $3 .^{\mathrm{a}}$ persona. ${ }^{13}$

En primer lugar, es destacable la presencia de la doble pauta pronominal para un mismo título, la cual contiene el germen del cambio: la alternancia de pronombres usted/tú, aunque este último sea minoritario, muestra las fisuras del sistema de tratamientos y anticipa la etapa siguiente con un predominio absoluto de camarada + tú. Por otro lado, es indiscutible que camarada no fue proclive al correlato pronominal tú, porque no cumplió con los requisitos de cercanía en la escala amistosa. El tú recíproco representaba el polo opuesto al usted como marcador pragmático del máximo grado de intimidad y venía determinado por dos condiciones obligadas y concurrentes: edad igual o similar de los dos miembros, así como conocimiento desde la infancia.

a. Hombre -me dijo con alguna impaciencia mi camarada- déjate de fantasmas y no me cuentes mortorios. (1725 Torres)

b. Tú vives aquí solo [...] Ya sabes que soy tu camarada. (1852 Cánovas)

Camarada no podía unirse a tú, pues representaba una intimidad menor que otros títulos más generales como, por ejemplo, amigo. Se han seleccionado cincuenta documentos del CNDH para estos dos siglos y se va a analizar amigo + pronombre, en la interacción:

12. Hay que destacar la enorme rentabilidad de usted recíproco en el XVIII y XIX como tratamiento prioritario en la mayoría de las relaciones, tanto solidarias como no solidarias, frente al tú minoritario (ver Calderón Campos; Medina Morales 2006; 2008).

13. El corpus registra 291 ocurrencias para estos siglos, de las que 107 reproducen la interlocución. 


\begin{tabular}{l|ll}
\hline Tú & $67.74 \%$ & $(42 / 62)$ \\
\hline Usted & $32.25 \%$ & $(20 / 62)$ \\
\hline
\end{tabular}

Tabla 15. Amigo en paradigmas de $2 .^{\mathrm{a}}$ y $3 .^{\mathrm{a}}$ persona.

Amigo se revela como un título de gran extensión semántica y marcador pragmático del máximo grado de cercanía frente a camarada, que, en un alto porcentaje de uso, estaba restringido a las relaciones amistosas entre hablantes de edades similares o distintas y no contraídas en la infancia. ${ }^{14}$ Por tanto, camara$d a$ marca una relación igualitaria, pero menos afectiva. ${ }^{15}$

\subsubsection{Camarada + usted recíproco entre amigos}

Indica que ambos eran de la misma edad o similar. El parámetro edad resulta primordial, pues, si no se cumpliera la sincronía etaria, se impone un esquema de trato asimétrico, que excluye la reciprocidad pronominal y, en consecuencia, el título igualitario camarada.

(24) Pues pare usted, camarada: / que no tengo otras narices / que ponerme, si me aplasta / estas que traigo. (1773 de la Cruz)

\subsubsection{Camarada + usted recíproco entre conocidos}

Camarada marca con claridad el vínculo amistoso y cobra un gran valor como estrategia de atenuación de la distancia, ya que, en esta etapa, el usted, impreciso y desgastado, abarca un espectro muy amplio de relaciones, desde las más cercanas a las más alejadas. ${ }^{16}$ Así pues, se revelaba como una técnica conversacional que da confianza al interlocutor (cortesía positiva). Aun así, camarada +

14. Usado incluso como título familiar (entre primos, entre tíos/sobrinos); también en una relación asimétrica en la jerarquía política o militar (de un superior a un inferior, donde el vínculo, aunque no excluye la amistad, haría presuponer otro tratamiento).

15. No se aprecia que, en el XVIII y XIX, camarada fuese una variable diastrática. No obstante, en el contexto rural reproducido en Peñas arriba de Pereda, es relevante la oposición amigo/camara$d a$ desde este punto de vista: la primera es usada en el trato entre los señores solariegos y la segunda aparece en boca del señorito aplicado a la clase inferior (Medina Morales 2008).

16. Un ejemplo a la inversa se localiza en el ámbito parlamentario, donde usted era implementado por formas nominales que aseguraban un tratamiento más formal y deferente; por otra parte, este era un hecho obligado por la legislación vigente para el estilo administrativo (ver GarcíaGodoy 2001-2002; 2005). 
usted no pierde la capacidad expresiva de respeto/deferencia propia de este periodo, simplemente el valor funcional se atenúa con el refuerzo nominal.

(25) Veo, camarada, que usted también lo entiende. (1876-1880 Zugasti)

\section{CAMARADA EN EL XX}

\subsection{Hacia el significado ideologizado}

Camarada se registra en todas las obras lexicográficas del xx como 'amigo': en las primeras publicaciones (Toro y Gómez, Pagés, Alemany y Rodríguez Navas), en todas las ediciones del DRAE, así como en las obras más recientes: $D E A$ y DUE. A partir de la edición de 1992, la RAE incluyó una nueva acepción: "En ciertos partidos y sindicatos, correligionario o compañero", que empieza a ser reproducida en los diccionarios, académicos y no académicos, hasta hoy. La Lexicografía no refleja la enorme vitalidad del término en el xx, esto es, la profusión de acepciones neológicas y la ebullición de usos que hemos conocido gracias al corpus documental. A diferencia del Siglo de Oro -etapa en que la polisemia fue apresurada y torrencial-, en esta centuria se pueden marcar diferentes estadios en la variación semántica, es decir, la polisemia neológica es secuencial, aunque la variación semántica, en general, no sea lineal, pues, en un mismo segmento de tiempo, conviven varias acepciones en alternancia, sin el desplazamiento radical de las más antiguas por las más recientes.

\begin{tabular}{l|c}
\hline 'amigo' & $20.47 \%(43 / 210)$ \\
\hline 'obrero' & $10.00 \%(21 / 210)$ \\
\hline 'obrero falangista' & $10.47 \%(22 / 210)$ \\
\hline 'obrero de izquierdas' & $6.60 \%(14 / 210)$ \\
\hline 'correligionario falangista' & $6.00 \%(16 / 210)$ \\
\hline 'correligionario comunista' & $44.76 \%(94 / 210)$ \\
\hline
\end{tabular}

Tabla 16. Frecuencia de las acepciones. ${ }^{17}$

17. Se documentan 210 ocurrencias en el xx, de las cuales 48 corresponden al primer tercio, 77 al segundo y 85 al último. 
En el cuadro, se segmenta el Xx en tres periodos para conocer las etapas del cambio semántico. Se constata la frecuencia absoluta de apariciones de camarada en cada tercio del siglo:

\begin{tabular}{l|c|c|c} 
& $1905-1932$ & $1933-1960$ & $1962-2002$ \\
\hline 'amigo' & $62.50 \%(30 / 48)$ & $5.10 \%(4 / 77)$ & $10.58 \%(9 / 85)$ \\
\hline 'obrero' & $37.50 \%(18 / 48)$ & $3.80 \%(3 / 77)$ & \\
\hline 'obrero falangista' & & $28.57 \%(22 / 77)$ & \\
\hline 'obrero de izquierdas' & & $18.18 \%(14 / 77)$ & \\
\hline 'correligionario falangista' & & $20.77 \%(16 / 77)$ & \\
\hline 'correligionario comunista' & & $23.37 \%(18 / 77)$ & $89.41 \%(76 / 85)$ \\
\hline
\end{tabular}

Tabla 17. Variación semántica en el xx.

La variación semántica más fructífera se produce en el segundo tercio del xx, época muy convulsa social y políticamente -preliminares, Guerra Civil y posguerra-. En esta etapa, camarada se activa en el uso y se muestra como una variable con una alta rentabilidad: aparecen nuevas acepciones, que se exhiben en contextos político-sociales diversos. Se refleja el debilitamiento de camarada como 'amigo' y 'obrero', y el avance de la nueva acepción 'correligionario', que se revela decisiva en sus especificaciones polarizadas ideológicamente, 'correligionario falangista' y 'correligionario comunista'. Dicha acepción neológica es fruto del préstamo semántico importado por los falangistas, en primer término, de Italia (camerata), y, de forma secundaria, de Alemania (Kamerad). De manera paralela y concurrente, dicho préstamo fue adoptado por los comunistas, pues la voz del ruso tovarishch (inicialmente 'hermano en el comercio'), usada entre los bolcheviques rusos como título igualitario, se tradujo al español como camarada.

El uso por parte de los comunistas tiene una gran trascendencia para el futuro de camarada, que, desde el último tercio del xx hasta la actualidad, se ha conservado en español con el significado de 'correligionario comunista', el más frecuente a partir de la década de los cincuenta. Dicha acepción privilegiada usurpó el hueco al resto: desapareció 'correligionario falangista', en primer lugar, por motivos históricos ligados a la desaparición 
del partido, ${ }^{18}$ a los que se unió la convivencia en una polisemia incómoda con el título usado entre los comunistas; tampoco se mantuvo con el significado de 'amigo' a no ser que el documento se alineara en un contexto de izquierdas.
a) 'amigo'

El más frecuente en el primer tercio del xx, junto al de 'obrero'. Decayó a partir de los 50 .

(26) ¿No pueden un hombre y una mujer ser amigos simplemente? ¿No podría usted ser un Buen camarada y tratarme como a un compañero? (1918 Blasco)

b) 'obrero'

(27) Varios obreros gallegos de este oficio van a acompañar el entierro de un camarada suyo. (1944 Laín)

c) 'correligionario falangista'

En la década de los treinta, el fascismo italiano, que se presentó, desde el principio, como el partido de los obreros, empleó camarata como tratamiento entre los correligionarios, ${ }^{19} \mathrm{y}$ el nazismo alemán, con idéntico propósito, se sirvió de Kamrade. Los falangistas adoptaron este significado como préstamo semántico del italiano, en primer término, fortalecido después por el alemán, aunque compartieran con ellos menos intereses ideológicos (Thomàs). En el franquismo, se conservó camarada como título igualitario mientras los falangistas dominaron el aparato del estado; después, con el nacionalcatolicismo, comenzó a extinguirse entre ellos, hasta su práctica desaparición en los cincuenta, pues recordaba una época férrea de la Dictadura, al tiempo que, polisémicamente, se identificaba con el título de tratamiento usado por los comunistas (Cuenca).

18. En la actualidad, Falange Española ha vuelto a emerger y entre sus miembros se ha recuperado el antiguo tratamiento de camarada. No obstante, carece de popularidad y no tiene ninguna extensión social (https://falange.es/).

19. En Italia, camarata era, hasta el gobierno de Mussolini, el tratamiento usado entre los obreros miembros de las asociaciones sindicales (ver Tortella); igualmente, su traducción en Inglaterra, Alemania o Francia. 
a. En los comienzos del otoño de 1937 tuve con el falangista Dionisio Ridruejo, mi primer contacto directo y personal como camarada. (1944 Laín)

b. Eugenio Montes -a quien Sánchez Mazas llamó "mi mayor y mejor camarada en el afán de poner las letras [...]" (2001 Cercas)

d) 'correligionario comunista'

Significado que ha triunfado, relevando a los demás. Camarada hoy es un título nominal igualitario restringido a esta adscripción ideológica.

a. Las Secciones campesinas, y especialmente los jóvenes camaradas, deben movilizarse. (1934 Anónimo)

b. Esto no es una guerra patriotera / Es la guerra de clases / ¿Verdad, combatientes? / Camaradas que ponéis al sol los muñones. (1937 Indignación)

e) 'obrero falangista'

En el ideario de Falange Española, se contenía la necesidad de un estado sindical totalitario, en el que la lucha de clases se superaría con un sindicato vertical que agruparía a empresarios y trabajadores (Thomàs).

(30) Os invitamos, pues, camaradas obreros, a fortalecer nuestro frente de lucha, bien perteneciendo a las JONs [...] bien formando en los Grupos de Oposición Nacionalsindicalista. (1933 fONS)

f) 'obrero de izquierdas'

Aglutina a obreros socialistas, anarquistas y comunistas.

a. Pasa el féretro, sencillo / en hombros de camaradas / las banderas de la FAI / CNT lo tapan. (1936 CNT)

b. Y yo, entonces, aconsejé a mis camaradas que declarásemos la huelga revolucionaria. (1948 Mihura) 


\subsection{El título nominal camarada en la deixis personal}

En el Xx, destaca el fortalecimiento de camarada como un título igualitario que expresa un vínculo no ya de amistad, sino de convergencia en intereses ideológicos o sindicales. En este sentido, se observa una elevada rentabilidad del título integrado en esquemas de deixis personal, empleados, en la mayoría de las situaciones, como vocativo:

\begin{tabular}{l|ll}
\hline Vocativo & $72.38 \%$ & $(152 / 210)$ \\
\hline Referencial & $27.60 \%$ & $(58 / 210)$ \\
\hline
\end{tabular}

Tabla 18. Usos vocativos..$^{20}$

Abajo, se analiza el empleo de camarada estrictamente como vocativo, la función de mayor rendimiento, ya que en esta se despliegan todos los patrones sintácticos en los que se inserta dicho título:

\begin{tabular}{l|cc}
\hline Camarada & $11.18 \%$ & $(17 / 152)$ \\
\hline Camarada + nombre personal & $31.57 \%$ & $(48 / 152)$ \\
\hline Camarada + nombre + apellido & $26.97 \%$ & $(41 / 152)$ \\
\hline Camarada + apellido & $25.00 \%$ & $(38 / 152)$ \\
\hline Camarada + título & $5.20 \%$ & $(8 / 152)$ \\
\hline
\end{tabular}

Tabla 19. Estructuras sintagmáticas.

Camarada se manifiesta inserto en estructuras aposicionales simples que evitan la complicación sintagmática y estilística, al tiempo que refuerzan su valor pragmático Por otra parte, dicha variable no se muestra dependiente de la tipología textual ni de la variación semántica, en este caso, la adscripción a ideologías de derechas o izquierdas.

El sistema de deixis personal tiende a codificarse de diferentes formas, de entre las que se destaca por su alta rentabilidad camarada en coaparición con el nombre personal y, en segundo lugar, este seguido del apellido. En

20. Hay una frecuencia absoluta de 210 ocurrencias para el xx. 
contextos políticos y sindicales, camarada se convierte así en un título solidario que garantiza la cortesía social y la consideración independientemente de la estructura sintáctica en que se integre: sería un trato no marcado, estereotipado, equivalente a un título general en la lengua cotidiana como don + nombre personal o señor + apellido, en cuanto que asegura la cortesía elemental.

Por otra parte, la equivalencia pragmática de las cuatro primeras variantes sintácticas descritas se traduce en la similitud entre ellas en cuanto a la frecuencia de uso, así como en cuanto a sus consecuencias diacrónicas, pues $c a-$ marada perdura hasta hoy integrado en gran medida en estructuras de ese tipo.

(32) Mira, camarada. Este es el camarada Kolzoff de Pravda e Izvestia. (1951 Barea)

a) Camarada + nombre propio

Como fórmula más cercana, aparece en más situaciones o para un mayor número de interlocutores, por lo que se convierte en la estructura más rentable.

(33) Oye, camarada Mateo, yo quería hacerte una observación. (1933 Falcón)

b) Camarada + nombre + apellido

(34) Quien fue el indicador del asesinato del camarada Joaquin de Grado. (1934 Anónimo)

c) Camarada + apellido

(35) Ante la embajada italiana, pronunció ayer un discurso el camarada Ridruejo delegado de Prensa y Propaganda de FET y de las JONS. (1937 Anónimo)

d) Camarada + título

Estructura menos rentable, pues, al marcar el estatus o la jerarquía, se aleja de los principios de igualdad inherentes a camarada en este periodo.

(36) Entendemos, camarada ministro, que, si tú lo autorizas, el Gobierno Civil se limitará. (1981 Del Val) 


\subsection{El tuteo recíproco como norma}

En el xx, destaca la supremacía de la díada camarada + tú recíproco, esto es, del esquema de tratamiento simétrico solidario.

\begin{tabular}{l|ll}
\hline Tú & $85.52 \%$ & $(130 / 152)$ \\
\hline Usted & $14.47 \%$ & $(22 / 152)$ \\
\hline
\end{tabular}

Tabla 20. Frecuencia de camarada en paradigmas de $2 .^{a}$ y $3 .^{a}$ persona. ${ }^{21}$

En los siglos XVIII y XIX, el esquema de respeto camarada + usted era prioritario (ver 7.3), por lo que es muy relevante el cambio sustancial en la pauta del tratamiento que tuvo lugar en un lapso diacrónico tan corto. Solamente factores extralingüísticos, cambios sociales urgentes, dan respuesta a esta cuestión. Abajo se segmenta el XX en tres periodos para conocer los distintos estadios del cambio.

\begin{tabular}{l|c|c|c} 
& $1905-1932$ & $1933-1960$ & $1962-2002$ \\
\hline Camarada + tú & $38.80 \%(14 / 36)$ & $100.00 \%(49 / 49)$ & $100.00 \%(67 / 67)$ \\
\hline Camarada + usted & $61.10 \%(22 / 36)$ & & \\
\hline
\end{tabular}

Tabla 21. Esquema de tratamiento en el xx.

A continuación, correlacionamos la variable semántica y la pauta pronominal para determinar cuáles fueron las acepciones más expuestas al cambio.

\begin{tabular}{l|c|c} 
& Usted & Tú \\
\hline 'amigo' & $14.47 \%(22 / 152)$ & \\
\hline 'correligionario falangista' & & $18.42 \%(28 / 152)$ \\
\hline 'correligionario comunista' & & $28.28 \%(43 / 152)$ \\
\hline
\end{tabular}

Tabla 22. Correlación de la variable semántica y la pauta pronominal. ${ }^{22}$

21. El corpus registra 210 ocurrencias para este periodo, de las que 152 reproducen la interacción.

22. De las 152 ocurrencias, hemos seleccionado las que tiene un significado relevante a la hora de determinar la pauta pronominal (93). El resto de ocurrencias tiene otras acepciones no determinantes. 
En el primer tercio, todavía está presente como correlato pronominal usted, incluso hay casos aislados de su merced entre hablantes de baja extracción social. Aquí, es determinante la correlación con el significado, pues este esquema está limitado a la acepción de 'amigo':

(37) Siéntese su mercé en el corro, camará; beba, cante. (1905 Blasco)

a. ¿Son todas las mujeres de esta traza como usté las pinta, camarada? (1926 Ayala Tigre)

b. Le habrá quedado seca la boca, camarada. (1926 Ayala Curandero)

A partir de la acepción neológica 'correligionario falangista' (1933), ${ }^{23}$ se produce el cambio sociolingüístico hacia el tú recíproco en la totalidad de ocurrencias, con independencia del significado, así como de parámetros sociales o pragmáticos. Respecto de los acontecimientos históricos que explican el cambio sociolingüístico, hay que poner de relieve que el fundador de Falange, J. A. Primo de Rivera, muy influido por el fascismo italiano, quiso emular la estrategia de Mussolini. Este, entre los signos externos del partido, adoptó la camisa negra y el tratamiento igualitario camarata + tuteo recíproco; en España, la versión joseantoniana radicaba también en el atuendo, camisa azul mahón, e idéntico esquema de trato (Thomàs). Dicho cambio, determinado por la ideología falangista, quedó reflejado de forma paralela y concurrente en la pauta de tratamiento de camarada como 'correligionario comunista'. De un lado, los correligionarios comunistas compartían con los falangistas la creencia en la sociedad sin clases; de otro, con el tuteo recíproco reproducían el tratamiento impuesto en Rusia para el título tovarishch 'camarada'. No se constata, a partir de 1933, ningún caso que pueda interpretarse como transición entre un esquema de trato y otro, es decir, no hay casos puente, usos de usted con dichas acepciones.

a. Te enterarías antes, camarada, si leyeras el papel al derecho. (1939 Azaña)

b. Como ves, camarada, no hay nada que hacer. (1951 Barea)

c. ¿Ves esto, camarada? ¿Sabes lo que es? (1993 Marsé)

23. El documento fundacional de la Falange Española se publica en 1933 (ver 1933 Anónimo $M a$ nifiesto) y, unidas a él, aparecen canciones y proclamas en las que el tuteo es explícito. 


\section{Conclusiones}

Del análisis precedente, se pueden extraer las siguientes conclusiones, vertebradas en tres apartados: semánticas, sintáctico-pragmáticas y referentes al patrón de tratamiento.

a) Semánticas

Camarada se documenta, por vez primera, en el XVI, con el significado de 'soldado’ y se extiende como préstamo por toda Europa. En el español áureo, emergieron gran cantidad de acepciones que prueban su vitalidad y elevada frecuencia de uso. En el XVIII y XIX, el itinerario fue menos estable: en el XVIII, destaca su baja rentabilidad y alta dependencia del tipo textual, ya que se privilegió la acepción de 'soldado'; en el XIX, se reactivó su empleo, rescatándose algunas de las acepciones áureas, las cuales, al ganar fuerza, favorecieron la incorporación de significados neológicos importados de Europa, en dos reemplazos: a finales del XIX y comienzos del XX. Así pues, camarada se conforma en la historia de nuestro léxico como un préstamo de ida y vuelta.

\section{b) Sintáctico-pragmáticas}

En el XVI y XVII, camarada se integra en estructuras sintagmáticas de cierta complejidad, formulismos que aglutinan varios títulos, con elevada fijación y un uso frecuente por su notable valor semántico-pragmático. En el XVIII y XIX, se detecta una nueva sensibilidad en el tratamiento, mayor predisposición a la sencillez, lo que se traduce en la simplificación de estas estructuras: fórmulas más cercanas que se adecúan al trato afectuoso y apartan otros convencionalismos sociales. En el xx, camarada se afianza como título igualitario y manifiesta una alta rentabilidad como vocativo: aumenta su fuerza pragmática en la deixis personal, al tiempo que disminuye su complicación en fórmulas.

c) Patrón de tratamiento

En el XVI y XVII, camarada se revela como un tratamiento solidario que puede aparecer tanto en contextos familiares (tuteo o voseo), como formales (v.m.). En los primeros, obtenía un mayor rendimiento, en tanto que la frecuencia de uso disminuía vinculado a la formalidad, lo cual repercutía en el aumento de su fuerza pragmática como marcador que aseguraba la cercanía. El XVIII y el XIX estuvieron caracterizados por el predominio de la formalidad, la cual determinaba tanto las relaciones asimétricas como simétricas y, en consecuencia, un vínculo como la amistad. El ustedeo recíproco se establece como la pauta 
de mayor rentabilidad, tanto entre amigos como entre conocidos; en este último caso, camarada encarna una estrategia de atenuación de la distancia. A partir del segundo tercio del Xx, hay una supremacía absoluta de la díada $c a-$ marada + tuteo recíproco, impuesta por los acontecimientos político-sociales.

Por último, hay que añadir que este estudio no deja de ser parcial, si no viene completado con el análisis de camarada en documentos hispanoamericanos, que pueden desvelar importantes diferencias, no solo desde el punto de vista semántico, sino también en cuanto a la pauta de tratamiento. Pero eso ya es otra investigación.

\section{OBRAS CITADAS}

Fuentes

[1552 Núñez Alba]: Diego Núñez de Alba. Diálogos de la vida del soldado. 1552. Ed. Antonio María Fabié. Madrid: Bibliófilos, 1890.

[1558 Anónimo]: Anónimo. Viaje de Turquía. 1558. Ed. Marie Sol Ortola. Madrid: Castalia, 2000.

[1568 Londoño]: Sancho de Londoño. Discurso sobre la forma de reducir la disciplina militar a mejor y antiguo estado. 1568. Madrid: Blass, 1943.

[1580 Ávila/Arguijo]: Hernando de Ávila y Juan Arguijo. La tragedia de San Hermenegildo. 1580. Ed. Julio Alonso Asenjo. Madrid: UNED/Valencia: Universidad/Sevilla: Universidad, 1995.

[1593 Isaba]: Marcos de Isaba. Cuerpo enfermo de la milicia española. 1593. Ed. Consuelo Maqueda. Madrid: Ministerio de Defensa, 1991.

[1599 Alemán]: Mateo Alemán. Primera parte de Guzmán de Alfarache. 1599. Ed. José María Micó. Madrid: Cátedra, 1992.

[1602 Luján]: Mateo Luján de Saavedra. Segunda parte de la vida del pícaro Guzmán de Alfarache. 1602. Ed. Florencio Sevilla. Madrid: Castalia, 2001.

[1605 López Úbeda]: Francisco López de Úbeda. La picara fustina. Ed. Antonio Rey. Madrid: Editora Nacional, 1977.

[1606 Lope Vega]: Lope de Vega Carpio. El asalto de Mastrique por el Principe de Parma. 1606. Alicante: Biblioteca Virtual Cervantes, 2002.

[1607-1645 Estrada]: Diego Duque de Estrada. Comentarios del desengañado de sí mismo. Vida del mismo autor. 1607-1645. Ed. Henry Ettinghausen. Madrid: Castalia, 1982.

[1611 Quevedo]: Francisco de Quevedo. Vida de la corte y Capitulaciones matrimoniales. 1611. Ed. Celsa Carmen García Valdés. Madrid: Cátedra, 1993. 
[1612 Castro]: Miguel de Castro. Vida de Miguel de Castro. 1612. Ed. José María de Cossío. Madrid: Atlas, 1956.

[1613 Vélez]: Luis Vélez de Guevara. La serrana de la Vera. 1613. Ed. Enrique Rodríguez. Madrid: Alcalá, 1967.

[1619 García]: Carlos García. La desordenada codicia de los bienes ajenos. 1619. Ed. Fernando Gutiérrez. Barcelona: Selecciones Bibliófilas, 1959.

[1629 Calderón]: Pedro Calderón de la Barca. Casa con dos puertas. 1640. Ed. Vda. de Juan Sánchez. Alicante: Centro Virtual Cervantes, 2000.

[1641 Vélez]: Luis Vélez de Guevara. El diablo cojuelo. 1641. Ed. Ramón Valdés. Barcelona: Crítica, 1999.

[1725 Torres]: Diego Torres Villarroel. Correo del otro mudo. 1725. Ed. Manuel María Pérez López. Madrid: Cátedra, 2000.

[1767 De la Cruz]: Ramón de la Cruz. Las preciosas ridículas. 1767. Ed. Emilio Cotarelo. Madrid: Bailly-Baillière, 1915.

[1773 De la Cruz]: Ramón de la Cruz. Las escofieteras. 1773. Ed. Francisco Lafarga. Madrid: Cátedra, 1990.

[1847 Estébanez]: Serafín Estébanez Calderón. Escenas andaluzas, bizarrías de la tierra [...]. 1847. Ed. Alberto González Troyano. Madrid: Cátedra, 1985.

[1852 Cánovas]: Antonio Cánovas Del Castillo. La campana de Huesca. Crónica del s. XII. 1852. Alicante: Biblioteca Virtual Cervantes/Universidad, 2003. [1863 Díaz]: Nicomedes-Pastor Díaz. Don Ramón Cabrera. 1863. Ed. José Luis Prieto. Barcelona: Fundación Caja Madrid/Anthropos, 1996.

[1871 Fernández]: Manuel Fernández y González. El guapo Francisco Esteban. Madrid: Imp. de D. Valero, 1871.

[1868 Pirala]: Antonio Pirala. Historia de la guerra civil y de los partidos liberal y carlista. 1868. Madrid: Turner, 1984).

[1876-1880 Zugasti]: Julián Zugasti y Sáenz. El Bandolerismo: estudio social y memorias históricas. 1876-1880. Ed. Virgilio Márquez. Córdoba: Excma. Diput., 1983.

[1885 Blasco]: Eusebio Blasco. Páginas intimas. 1885. Madrid: Librería de Leopoldo Martínez, 1905.

[1885-1887 Galdós]: Benito Pérez Galdós. Fortunata y facinta. 1885-1887. Ed. Miguel Ynduráin. Madrid: Turner, 1993.

[1886 Aller]: Domingo Enrique Aller. Las buelgas de los obreros. Madrid: Tipog. de los Huérfanos, 1886.

[1905 Blasco]: Vicente Blasco Ibáñez. La bodega. 1905. Ed. Francisco Caudet. Madrid: Cátedra, 1998. 
[1918 Blasco]: Vicente Blasco Ibáñez. Mare nostrum. 1918. Ed. M. José Navarro. Madrid: Cátedra, 1998.

[1926 Ayala Curandero]: Ramón Pérez de Ayala. El curandero de su honra. Ed. Andrés Amorós. Madrid: Castalia, 1991.

[1926 Ayala Tigre]: Ramón Pérez de Ayala. Tigre fuan. 1926. Ed. Andrés Amorós. Madrid: Castalia, 1991.

[1933 Anónimo Manifiesto]: Anónimo. "Manifiesto de la Falange". Falange Española 1 (7 diciembre 1933): 6-7.

[1933 Anónimo 7ONS]: Anónimo. "Las JONS a todos los trabadores de España: manifiesto del partido". Funtas de Ofensiva Nacional-Sindicalista 7.12 (1933).

[1933 Falcón]: César Falcón. El agente confidencial. 1933. Ed. Gonzalo Santonja. Madrid: Ayuso, 1979.

[1934 Anónimo]: Anónimo. "A los campesinos: una nota de la Federación Española de Trabajadores de la Tierra". El Socialista [Madrid] 18 septiembre 1934.

[1936 CNT]: CNT: romances publicados en la CNT [...]. 1936. Ed. Alberto González Troyano. Madrid: Cátedra, 1985.

[1937 Indignación]: Indignación: romances publicados en la CNT [...]. 1937. Ed. Alberto González Troyano. Madrid: Cátedra, 1985.

[1937 Anónimo]: Anónimo. "Esta noche habrá una gran manifestación [...]. Los manifestantes expresaron su adhesión ante las Embajadas de Alemania e Italia”. El Correo de Andalucía [Sevilla] 2 julio 1937.

[1939 Azaña]: Manuel Azaña. La velada en Benicarló: diálogo de la guerra de España. 1939. Ed. Manuel Aragón. Madrid: Castalia, 1980.

[1944 Baroja]: Pío Baroja. Desde la última vuelta del camino: memorias. 1944. Madrid: Biblioteca Nueva, 1978.

[1944 Laín]: Pedro Laín Entralgo. Fragmento. Ed. Dionisio Ridruejo. Poesía en armas. Madrid: Imp. de A. Aguado, 1944.

[1948 Mihura]: Miguel Mihura. Mis memorias. 1948. Barcelona: Ediciones Mascarón, 1981.

[1951 Barea]: Arturo Barea. La forja de un rebelde. 1951. Buenos Aires: Losada, 1958.

[1952-1956 Arias]: Gabriel Arias-Salgado. Textos de doctrina y política de la información. Madrid: Sec. Gen. del Ministerio de Información, 1952-1956. [1981 Del Val]: José María Del Val. Llegará tarde a Hendaya. 1981. Barcelona: Planeta, 1983.

[1993 Marsé]: Juan Marsé. El embrujo de Shangai. Barcelona: Plaza y Janés, 1993. [2001 Cercas]: Javier Cercas. Soldados de Salamina. Barcelona: Tusquets, 2001. 


\section{Estudios}

Alonso Hernández, José Luis. El lenguaje de los maleantes españoles de los siglos XVI у XVII: la germanía. Salamanca: Universidad, 1977.

Álvarez de Miranda, Pedro. Palabras e ideas: el léxico de la Ilustración temprana en España (1680-1760). Madrid: RAE, 1992.

Álvarez de Miranda, Pedro. "Las discontinuidades en la Historia del léxico". Actas del VII Congreso Internacional de Historia de la Lengua Española. Eds. Concepción Company y José. G. Moreno de Alba. Madrid: Arco Libros, 2008. 1-44.

Brown, Penelope, y Stephen C. Levinson. Politeness: Some Universals in Language Usage. Cambridge: Cambridge UP, 1987.

Brown, Roger, y Albert Gilman. "The Pronouns of Power and Solidarity". Style in Language. Ed. Thomas Albert Sebeok. New York: The MIT Press, 1960.

Calderón Campos, Miguel. "Las fórmulas de tratamiento sociales en obras literarias andaluzas de la segunda mitad del siglo XIX". Cuadernos del Sur 31 (2001): 7-35.

Chamorro, María Isabel. Tesoro de villanos: diccionario de la germanía. Barcelona: Herder, 2002.

CNDH: Real Academia Española. Corpus del Nuevo diccionario histórico del español. <http://web.frl.es/DH>. [enero de 2020].

Comellas, José Luis. Historia de España en el siglo XIX. Madrid: Rialp, 2017.

Correas, Gonzalo. Arte castellana. 1627. Ed. Manuel Taboada Cid. Santiago de Compostela: Universidad, 1984.

Cuenca Toribio, J. M. Nacionalismo, franquismo y nacionalcatolicismo. Madrid: Actas, 2008.

DEA: Manuel Seco, Andrés Olimpia y Gabino Ramos. Diccionario del español actual. Madrid: Aguilar, 2011.

DRAE: Real Academia Española. Diccionario de la lengua española. <dle.rae.es>. [enero 2020].

DUE: María Moliner. Diccionario de uso del español. 4. ${ }^{a}$ ed. Madrid: Gredos, 2016.

García-Godoy, M. ${ }^{a}$ Teresa. El léxico del primer constitucionalismo español y mejicano (1810-1815). Granada: Universidad, 1999.

García-Godoy, M. ${ }^{\text {a }}$ Teresa. "De majestad a señores diputados: la evolución de las fórmulas de tratamiento en los orígenes del parlamentarismo argentino (1810-1861)". Anuario de Lingüística Hispánica 17-18 (2001-2002): 11-24. 
García-Godoy, M. ${ }^{a}$ Teresa. "Estilo cortés y tratamiento honoríficos en los orígenes del constitucionalismo argentino". Revista Internacional de Lingüistica Iberoamericana 3.1 (2005): 79-96.

Hidalgo, Juan. Vocabulario de germanía. 1609. Ed. Antonio Sancha. Madrid, 1779.

Martínez de Velasco, Luis. Las revoluciones industriales hoy. Madrid: Santillana, 1997.

Marx, Karl, y Friedrich Engels. Manifiesto del Partido comunista. 1848. Obras escogidas. Madrid: Akal, 1975.

McPhee, Peter. La revolución francesa (1789-1799). Barcelona: Crítica, 2003.

Medina Morales, Francisca. "Cortesía y descortesía en el español de la Edad de Oro a la luz de un complejo sistema lingüístico de tratamientos". Analecta Malacitana 28.1 (2005a): 101-40.

Medina Morales, Francisca. El léxico de la novela picaresca. Anejos de Analecta Malacitana 57. Málaga: Analecta Malacitana, 2005b.

Medina Morales, Francisca. "La cortesía verbal en la segunda mitad del siglo XIX: estudio de los tratamientos en la novela Pepita fiménez de Juan Valera". La vida cotidiana andaluza a través de los documentos con valor historicolinguístico y dialectal. Ed. M. ${ }^{a}$ Isabel Montoya. Granada: Universidad, 2006. 212-34.

Medina Morales, Francisca. "Tratamientos nominales y cortesía en la novela Peñas arriba de J. M. De Pereda”. Forma y Función, 21 (2008): 135-55.

NTLLE: Real Academia Española. Nuevo tesoro lexicográfico de la lengua española. $<$ http://ntlle.rae.es/ntlle/SrvltGUILoginNtlle>. [enero de 2020].

Olliver, Jean Paul. ¿¿Cuándo amanecerá, camarada?: crónica de la Revolución rusa (1876-1917). Madrid: Clave Intelectual, 2017.

Parker, Geoffrey. El ejército de Flandes y el camino español (1567-1659). Madrid: Alianza, 2016.

Rudé, George. El rostro de la multitud: estudios sobre revolución, ideología y protesta popular. Valencia: Historia Social, 2000.

Thomàs, Joan Maria. Fosé Antonio: mito y realidad. Barcelona: Debate, 2017.

Tortella, Gabriel. La revolución del siglo XX: capitalismo, comunismo y democracia. Madrid: Taurus, 2000. 